\title{
Annual peritoneal dialysis report 2014, the peritoneal dialysis registry
}

\author{
Ikuto Masakane ${ }^{1,4^{*}}$, Takeshi Hasegawa², Satoshi Ogata', Naoki Kimata', Shigeru Nakai', Norio Hanafusa', \\ Takayuki Hamano ${ }^{1}$, Kenji Wakai', Atsushi Wada', Kosaku Nitta ${ }^{3}$, on behalf of the Committee of Renal Data Registry \\ (CRDR), the Japanese Society for Dialysis Therapy (JSDT)
}

\begin{abstract}
Background: Since 2009, the peritoneal dialysis (PD) registry has been carried out as part of Japanese Society for Dialysis Therapy (JSDT) Renal Data Registry with the cooperation of Japanese Society for Peritoneal Dialysis. In this study, the current status of PD patients is reported on the basis of the results of the survey conducted at the end of 2014.

Methods: The subjects were PD patients who lived in Japan and participated in the 2014 survey. Descriptive analysis was performed for various items including the current status of the combined use of PD and another dialysis modalities such as hemodialysis or hemodiafiltration, the method of exchanging PD fluid, the use of an automated peritoneal dialysis machine, and the incidences of peritonitis and catheter exit-site infection.

Results: From the results of the facility survey in 2014, the number of PD patients was 9255, a decrease of 137 from that in 2013. Among the entire dialysis patient population, $2.9 \%$ were PD patients, a decrease of $0.1 \%$. One thousand thirteen (21\%) among them were on the combination therapy of PD and hemodialysis or hemodiafiltration. The mean incidence of peritonitis was 0.21 per patient per year in another expression as once per 57.1 patients per month. The mean incidence of catheter exit-site infection was 0.40 per patient per year in the other expression as once per 30.0 patients per month.
\end{abstract}

Conclusions: The number of PD patients has been stable around 9000 10,000 in these 10 years. High percentage of the combination therapy of PD and other dialysis modality and the lower PD dialysis dose was a unique point of the current PD in Japan. The patient's and center's peritonitis rates were very low as around 0.2 per patient-year. PD registry clearly showed the current trends in PD in Japan which were a little different from those in other many countries.

Trial registration: JSDT renal data registry was approved by the ethical committee of JSDT and registered in "University hospital Medical Information Network (UMIN) Clinical Trials Registry" as an approved number of UMIN000018641 in 2015.

Keywords: PD registry, Dialysis fluid exchange maneuver, Peritonitis, Catheter exit-site infection

\section{Introduction}

Japanese Society for Dialysis Therapy (JSDT) has been conducting an annual survey on the current status of regular dialysis treatment in Japan (JSDT Renal Data Registry (JRDR)) at the end of each year since 1968. Since 1983, survey items relating to all dialysis patients

\footnotetext{
* Correspondence: imasakan.aipod@seieig.or.jp

${ }^{1}$ Committee of Renal Data Registry (CRDR), Japanese Society for Dialysis

Therapy (JSDT), Aramido Building 2F, 2-38-21 Hongo, Bunkyo-ku, Tokyo

113-0033, Japan

${ }^{4}$ Department Nephrology, Yabuki Hospital, 4-4-5 Shima Kita, Yamagata City,

Yamagata 990-0885, Japan

Full list of author information is available at the end of the article
}

treated in dialysis facilities that participated in the surveys have been included and the obtained data have been registered in an electronic database [1]. In the 2009 survey, JSDT started the peritoneal dialysis (PD) registry survey of patients who underwent $\mathrm{PD}$, in cooperation with Japanese Society for Peritoneal Dialysis (JSPD) [2]. The targets of the PD registry survey include facilities that offer PD alone, which were not targeted in the conventional surveys conducted at the end of each year. The results of the PD registry survey have been reported annually in the sections "Current status of PD treatment" and "Items associated with PD" of the "An 
Overview of Regular Dialysis Treatment in Japan" compiled by Committee of Renal Data Registry (CRDR) in JSDT. In 2012, the results of the PD registry survey were separated from the above overview and independently summarized in the PD registry survey report as an academic paper. The current manuscript is the second publication of "Peritoneal dialysis (PD) registry with 2014 survey report. J Jpn Soc Dial Ther 49(1):35-40, 2016," written in Japanese.

Here, the data obtained from the 2014 PD registry survey are summarized in the following six topics:

I. Current status of PD patients

II. Urine output and volume of water removed by $\mathrm{PD}$

III. Dialysate/plasma creatinine $(\mathrm{D} / \mathrm{P} \mathrm{Cr})$ ratio in a peritoneal equilibration test (PET)

IV. Kt/V for residual renal function (residual renal Kt/V) and $\mathrm{Kt} / \mathrm{V}$ for PD (PD Kt/V)

$\mathrm{V}$. Peritonitis and catheter exit-site infections

VI. Encapsulating peritoneal sclerosis (EPS)

\section{Outline of the PD registry in 2014}

\section{Survey methods}

This survey was conducted by sending questionnaires to individual dialysis facilities. A total of 4367 facilities participating in this survey were either member facilities of JSDT, nonmember facilities offering regular hemodialysis (HD), or nonmember facilities offering PD but not HD, as of December 31, 2014. The number of participating facilities increased by $42(1.0 \%)$ from the previous year (4325 facilities) [3]. Among the 4367 facilities, 986 treated PD patients.

Universal serial bus (USB) memory devices that stored electronic spreadsheets in Microsoft Excel ${ }^{\circ}$ or paper questionnaires were sent to and collected from the individual dialysis facilities, mainly by postal mail; for some facilities, the questionnaires were sent and collected by fax. In the 2014 survey, two sets of questionnaires were used. One was for the facility survey, which included items on individual dialysis facilities, such as the numbers of patients and staff members. The other was for the patient survey, which included items on individual dialysis patients, such as their demographical background, treatment conditions, and outcomes of treatment. The deadline for acceptance of responses was the end of January 2015. The acceptance of responses submitted after this deadline, including those of the additional surveys, ended on August 7, 2015.

Before 2014, the results from JRDR had been reported in the following three types of report. First, quick analyses of the data obtained by April in the following year were reported at the annual meeting of the JSDT held in June and compiled in "The Atlas, Overview of Regular Dialysis Treatment in Japan," Second, the responses to the survey had been continuously collected until September, and the obtained data were screened to determine the definite survey results, which were published in the "An Overview of Regular Dialysis Treatment in Japan, the CD-ROM Report." Third, the tabulated results based on the definite values in the CD-ROM Report were published as an annual dialysis data report in the Journal of Japanese Society for Dialysis Therapy. Therefore, the values in the atlas were different from the definite values in the CD-ROM. The quick estimations were prepared only for the atlas in the annual meeting of JSDT. However, the values in the atlas had been occasionally cited as if they were officially approved values because they were expressed by attractive graphs. To avoid these mal-citations, we decided to publish all the official reports from the 2014 survey based on the definite database.

For the CD-ROM Report, the number of facilities that responded to the facility survey was $4330(99.2 \%)$ and the number of those that responded to both the facility and patient surveys was 4191 (96.0\%) [4]. Moreover, the number of facilities that completed the questionnaires using the electronic medium was 3764 (86.9\%), which was higher than that in the 2013 survey (3698 facilities, 86.6\%). This increase contributed to the accurate and simplified analysis of survey data.

\section{Survey items}

The 2014 survey included the following survey items. For the items included in the previous surveys, refer to the membersonly pages of the JSDT website (http://member.jsdt.or.jp/ member/contents/data/research_list_2000-2015.pdf).

\section{Facility survey items}

- Name of facility, contact numbers (telephone and fax), name of representative (doctor), and name of respondent

- Year and month when the facility started offering dialysis treatment

Table 1 Number of prevalent PD patients

\begin{tabular}{ll}
\hline & $\begin{array}{l}\text { Number of } \\
\text { patients }\end{array}$ \\
\hline Prevalent PD patients & 9255 \\
$\begin{array}{l}\text { Patients with a catheter for PD } \\
\text { such as those who underwent only } \\
\text { peritoneal lavage }\end{array}$ & 278 \\
$\begin{array}{l}\text { New patients who started on PD } \\
\text { in } 2014 \text { but switched to other } \\
\text { methods in the same year }\end{array}$ & 193 \\
Patients who underwent PD + HD(F) & 1913 \\
\hline
\end{tabular}

These data were obtained by the facility survey 


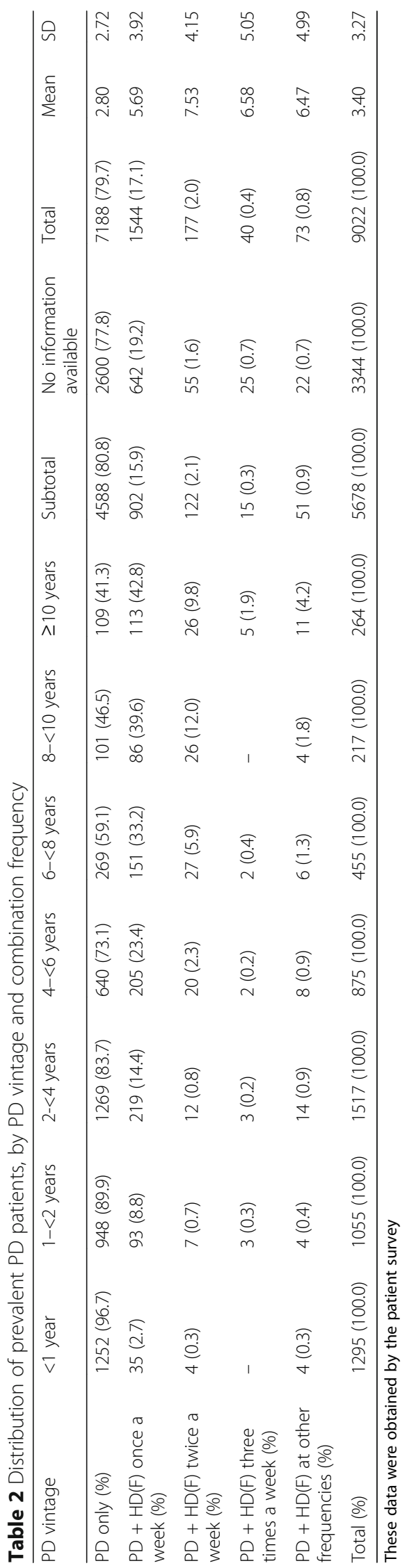


Table 3 Changing maneuver of PD fluids

\begin{tabular}{llllllll}
\hline $\begin{array}{l}\text { Method of PD } \\
\text { solution } \\
\text { exchange }\end{array}$ & $\begin{array}{l}\text { Completely } \\
\text { manual } \\
\text { exchange }\end{array}$ & $\begin{array}{l}\text { Double-bag } \\
\text { system with } \\
\text { ultraviolet } \\
\text { light irradiation }\end{array}$ & $\begin{array}{l}\text { Double-bag } \\
\text { system with sterile } \\
\text { connecting device }\end{array}$ & $\begin{array}{l}\text { Double-bag system } \\
\text { (methods other than } \\
\text { those on the left } \\
\text { columns, including } \\
\text { semimanual methods) }\end{array}$ & Subtotal & Unspecified & $\begin{array}{l}\text { No information } \\
\text { available }\end{array}$ \\
\hline Number of & $1422(32.2)$ & $2322(52.6)$ & $607(13.7)$ & $66(1.5)$ & $4417(100.0)$ & 76 & 2695
\end{tabular}

patients (\%)

These data were obtained from the PD-only patients in the patient survey

- Number of bedside consoles, total number of patients who can simultaneously receive dialysis, and maximum number of admissible patients

- Number of full-time and part-time workers engaged in dialysis treatment (e.g., doctors, nurses, clinical engineers, nutritionists, case workers)

- Number of dialysis doctors

- Number of outpatients and inpatients who underwent dialysis (daytime dialysis, nighttime dialysis, home HD, and PD)

- Number of prevalent dialysis patients at the end of 2014

- Number of new patients who were started incident dialysis patients in 2014

- Number of dialysis patients who died during 2014

- Number of patients who underwent HD or hemodiafiltration (HDF) and did not undergo PD despite having a catheter for PD (underwent only peritoneal lavage), number of patients who underwent both PD and HD or HDF, and number of new patients who were started on PD in 2014 but introduced to another blood purification method in the same year

- Current status of dialysate quality control (details not shown)

\section{Patient survey items}

The following are the basic survey items that have been annually surveyed since 1983 .

- Anonymized name

- Gender and date of birth

- Year and month of start of dialysis and year and month of transfer from another hospital

- Primary disease

- Prefecture where the patient lives

- Dialysis method

- Outcome, year, and month (transfer, death, change in dialysis method, or transplantation) (code of facility to which the patient is transferred)

- Cause of death

The following were added to the basic survey items and were surveyed using both paper and electronic media.

- Dialysis modality, current status of combined use of PD, and HD or HDF

- History of PD

- Number of renal transplantations

Table 4 Use or nonuse of APD machine, by PD vintage

\begin{tabular}{|c|c|c|c|c|c|c|}
\hline PD vintage & Use & Nonuse & Subtotal & Unspecified & $\begin{array}{l}\text { No information } \\
\text { available }\end{array}$ & Total \\
\hline$<1$ year (\%) & $627(52.8)$ & $561(47.2)$ & $1188(100.0)$ & 3 & 61 & 1252 \\
\hline $1-<2$ years (\%) & $451(50.0)$ & $451(50.0)$ & $902(100.0)$ & 2 & 44 & 948 \\
\hline $2-<4$ years (\%) & $672(55.8)$ & $532(44.2)$ & $1204(100.0)$ & 16 & 49 & 1269 \\
\hline $4-<6$ years (\%) & $340(55.6)$ & $272(44.4)$ & $612(100.0)$ & 7 & 21 & 640 \\
\hline $6-<8$ years $(\%)$ & $163(63.7)$ & $93(36.3)$ & $256(100.0)$ & - & 13 & 269 \\
\hline $8-<10$ years (\%) & $66(70.2)$ & $28(29.8)$ & $94(100.0)$ & 2 & 5 & 101 \\
\hline$\geq 10$ years $(\%)$ & $71(68.3)$ & $33(31.7)$ & $104(100.0)$ & - & 5 & 109 \\
\hline Subtotal (\%) & $2390(54.8)$ & $1970(45.2)$ & $4360(100.0)$ & 30 & 198 & 4588 \\
\hline $\begin{array}{l}\text { No information } \\
\text { available (\%) }\end{array}$ & $48(55.8)$ & $38(44.2)$ & $86(100.0)$ & - & 2514 & 2600 \\
\hline Total (\%) & $2438(54.8)$ & $2008(45.2)$ & $4446(100.0)$ & 30 & 2712 & 7188 \\
\hline Mean & 2.99 & 2.56 & 2.80 & 3.41 & 2.67 & 2.80 \\
\hline SD & 2.91 & 2.42 & 2.71 & 2.02 & 3.02 & 2.72 \\
\hline
\end{tabular}

These data were obtained from the PD-only patients in the patient survey

Values in parentheses under each figure represent the percentage relative to the total in each row $A P D$ automated peritoneal dialysis 


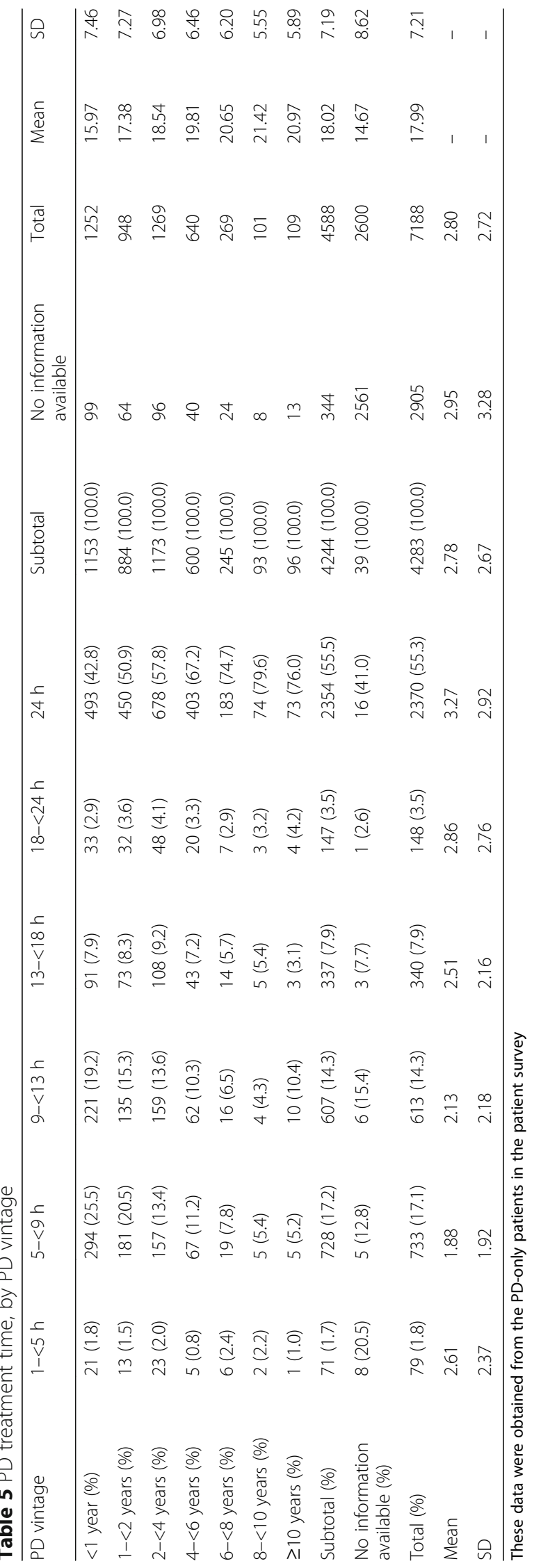




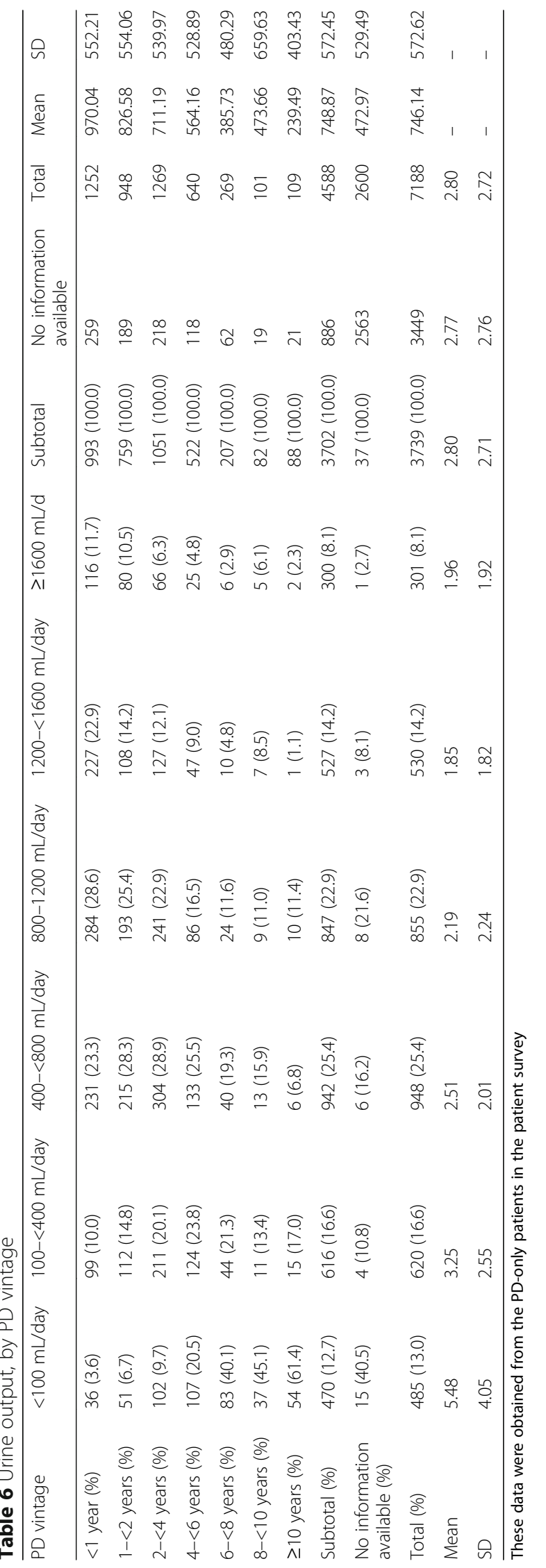




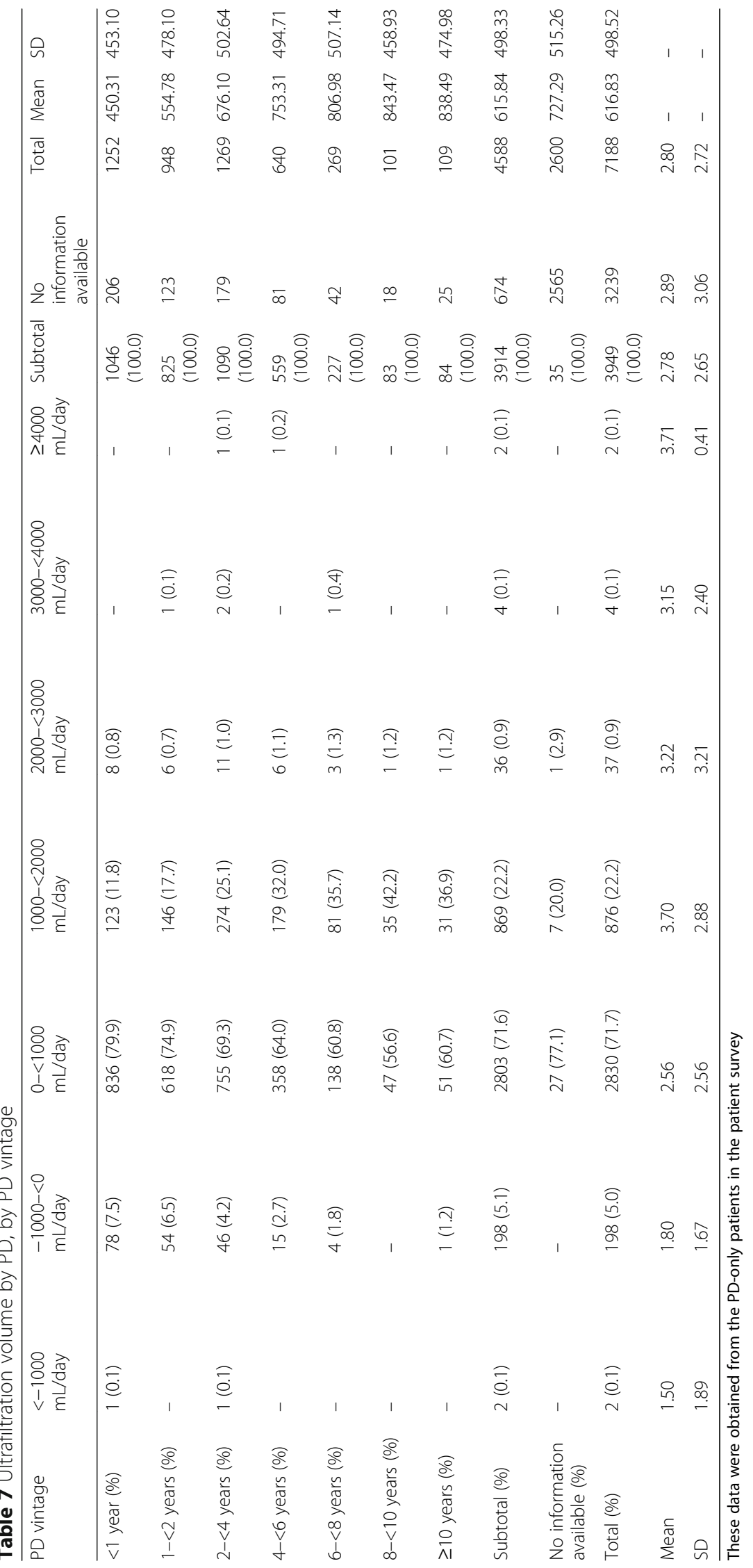


Table 8 History of PET

\begin{tabular}{|c|c|c|c|c|c|c|c|}
\hline $\begin{array}{l}\text { Performance or } \\
\text { nonperformance of PET }\end{array}$ & Not performed & PET performed & Fast PET only & Subtotal & Unspecified & $\begin{array}{l}\text { No information } \\
\text { available }\end{array}$ & Total \\
\hline Number of patients (\%) & $1513(34.5)$ & $1885(42.9)$ & $992(22.6)$ & $4390(100.0)$ & 90 & 2708 & 7188 \\
\hline
\end{tabular}

These data were obtained from the PD-only patients in the patient survey

- Frequency of dialysis per week, duration of one session of dialysis (min/session), and blood flow rate $(\mathrm{mL} / \mathrm{min})$ (for patients who underwent blood purification by extracorporeal circulation)

- Method of diluting HDF solution and volume of substitution fluid per HDF session (L) (for patients who underwent HDF)

- Height and predialysis and postdialysis body weights

- Predialysis and postdialysis serum blood urea nitrogen (BUN) (mg/dL) and creatinine $(\mathrm{mg} / \mathrm{dL})$ levels

- Predialysis albumin (g/dL), C-reactive protein (CRP) (mg/dL), calcium $(\mathrm{mg} / \mathrm{dL})$, phosphorus $(\mathrm{mg} / \mathrm{dL})$, and blood hemoglobin (g/dL) levels and parathyroid hormone $(\mathrm{PTH})(\mathrm{pg} / \mathrm{mL})$ levels and the measurement method of PTH
- Use or nonuse of antihypertensive drugs and smoking habit

- History of comorbidity (diabetes, myocardial infarction, cerebral hemorrhage, cerebral infarction, quadruple amputation, femoral neck fracture, and EPS)

\section{USB-only survey items}

Details of PD were surveyed as USB-only survey items separately from the abovementioned questionnaires for the facility and patient surveys. The following are the USB-only survey items associated with PD.

- PD vintage (months)

- Number of months when PD was performed in 2014

- Performance or nonperformance of PET

Table 9 Type of PD fluid, by PET D/P Cr ratio

\begin{tabular}{|c|c|c|c|c|c|c|c|c|c|}
\hline Type of PD fluid & $<0.5$ & $0.5-<0.65$ & $0.65-<0.81$ & $\geq 0.81$ & Subtotal & No information available & Total & Mean & SD \\
\hline $\begin{array}{l}1.5 \% \text { dextrose } \\
\text { only (\%) }\end{array}$ & 143 (61.9) & 485 (55.6) & 402 (39.7) & $103(31.2)$ & 1133 (46.3) & $958(46.5)$ & 2091 (46.4) & 0.63 & 0.13 \\
\hline $\begin{array}{l}1.5 \text { and } 2.5 \% \\
\text { dextrose }(\%)\end{array}$ & $26(11.3)$ & $110(12.6)$ & $128(12.6)$ & $29(8.8)$ & $293(12.0)$ & $272(13.2)$ & $565(12.5)$ & 0.65 & 0.14 \\
\hline $\begin{array}{l}2.5 \% \text { dextrose } \\
\text { only (\%) }\end{array}$ & $1(0.4)$ & $11(1.3)$ & $22(2.2)$ & $11(3.3)$ & $45(1.8)$ & $81(3.9)$ & $126(2.8)$ & 0.71 & 0.12 \\
\hline $\begin{array}{l}4.25 \% \text { dextrose } \\
\text { only } \\
\text { (without } \\
\text { icodextrin) (\%) }\end{array}$ & $1(0.4)$ & $1(0.1)$ & - & - & $2(0.1)$ & $5(0.2)$ & $7(0.2)$ & 0.44 & 0.21 \\
\hline $\begin{array}{l}\text { Icodextrin only } \\
\text { (without dextrose) } \\
(\%)\end{array}$ & $2(0.9)$ & $7(0.8)$ & $7(0.7)$ & $4(1.2)$ & $20(0.8)$ & $31(1.5)$ & $51(1.1)$ & 0.70 & 0.16 \\
\hline $\begin{array}{l}1.5 \% \text { dextrose + } \\
\text { icodextrin }(\%)\end{array}$ & $37(16.0)$ & $146(16.7)$ & $275(27.1)$ & $108(32.7)$ & $566(23.1)$ & $439(21.3)$ & 1005 (22.3) & 0.69 & 0.13 \\
\hline $\begin{array}{l}1.5 \text { and } 2.5 \% \\
\text { dextrose }+ \\
\text { icodextrin (\%) }\end{array}$ & $10(4.3)$ & $68(7.8)$ & $111(11.0)$ & $42(12.7)$ & $231(9.4)$ & $135(6.6)$ & $366(8.1)$ & 0.69 & 0.13 \\
\hline $\begin{array}{l}2.5 \% \text { dextrose }+ \\
\text { icodextrin (\%) }\end{array}$ & $11(4.8)$ & $44(5.0)$ & $66(6.5)$ & $33(10.0)$ & $154(6.3)$ & $140(6.8)$ & $294(6.5)$ & 0.68 & 0.16 \\
\hline $\begin{array}{l}4.25 \% \text { dextrose + } \\
\text { icodextrin (\%) }\end{array}$ & - & $1(0.1)$ & $2(0.2)$ & - & $3(0.1)$ & - & $3(0.1)$ & 0.67 & 0.12 \\
\hline Subtotal (\%) & $231(100.0)$ & $873(100.0)$ & $1013(100.0)$ & $330(100.0)$ & $2447(100.0)$ & $2061(100.0)$ & $4508(100.0)$ & 0.66 & 0.14 \\
\hline Unspecified & 5 & 19 & 9 & 2 & 35 & 13 & 48 & 0.59 & 0.15 \\
\hline $\begin{array}{l}\text { No information } \\
\text { available }\end{array}$ & 3 & 8 & 17 & 3 & 31 & 2601 & 2632 & 0.67 & 0.11 \\
\hline Total & 239 & 900 & 1039 & 335 & 2513 & 4675 & 7188 & 0.66 & 0.14 \\
\hline
\end{tabular}

These data were obtained from the PD-only patients in the patient survey 


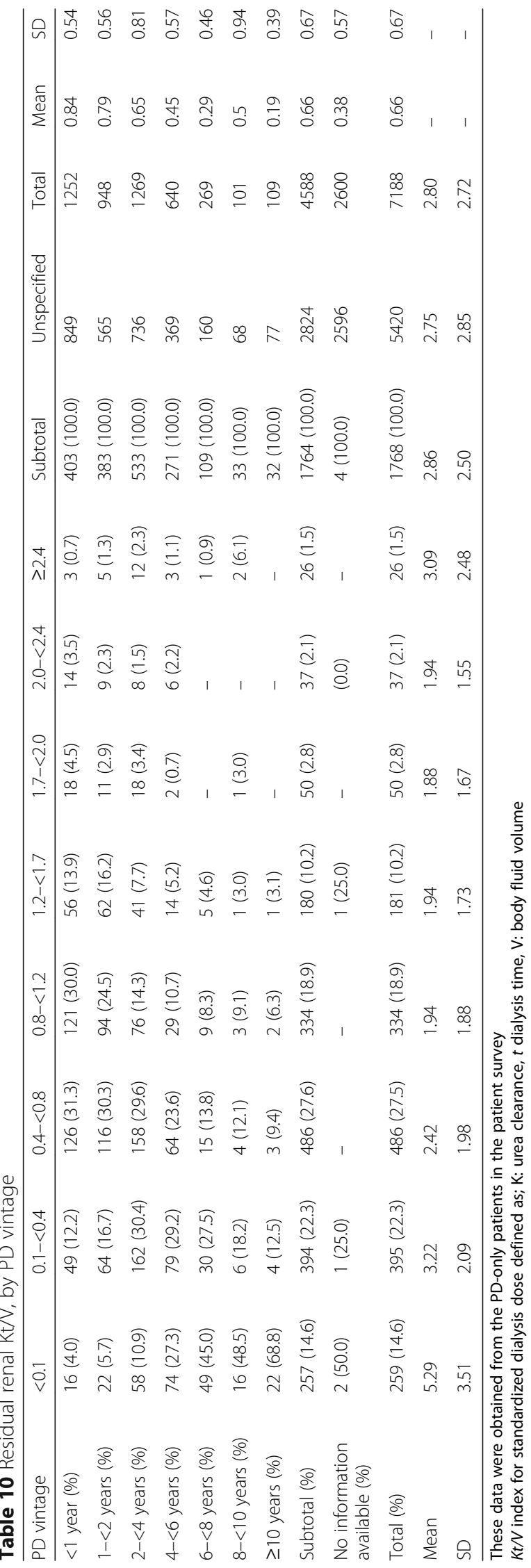




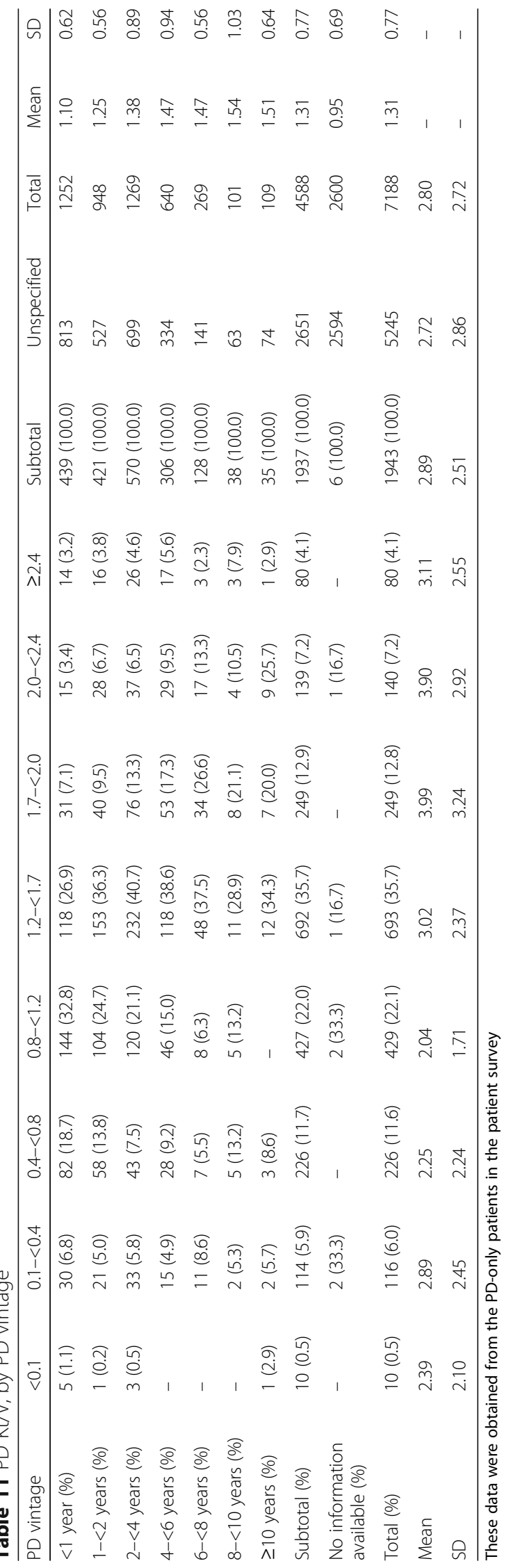


Table 12 Patient's peritonitis rate

\begin{tabular}{llllllllll}
\hline $\begin{array}{l}\text { Peritonitis episodes } \\
\text { per patient-year }\end{array}$ & 0 & $1.0-<2.0$ & $2.0-<3.0$ & $3.0-<4.0$ & $4.0-<5.0$ & $\geq 5.0$ & Subtotal & $\begin{array}{l}\text { Unspecified/no } \\
\text { information available }\end{array}$ & $\begin{array}{l}\text { Total } \\
\text { Mean }\end{array}$ \\
\hline Number of patients (\%) & $3758(86.7)$ & $400(9.5)$ & $82(2.3)$ & $25(0.8)$ & $13(0.3)$ & $23(0.4)$ & $4301(100.0)$ & 2887 &
\end{tabular}

These data were obtained from the PD-only patients in the patient survey

Patient's peritonitis rate per patient-year $=($ Peritonitis episodes in 2014 in all subjects $\div$ Total months on PD in 2014 in all subjects $) \times 12$

- PET-derived 4-h dialysate/plasma creatinine ratio (PET D/P Cr ratio)

- Type of PD fluid

- Volume of PD fluid per day

- Remaining renal function (daily urine output)

- Mean ultrafiltration (UF) volume per day (UF volume)

- Residual renal Kt/V and PD Kt/V

- Changing maneuver of PD fluids

- Use or nonuse of automated peritoneal dialysis (APD) machine

- PD treatment time per day

- Past history of peritonitis during 2014

- At history of catheter exit-site infections (ESI) in 2014

\section{Results and discussion}

\section{Current status of PD patients}

\section{Number of patients}

According to the facility survey, the number of PD patients was 9255 at the end of 2014, a decrease of 137 from the previous year. The percentage of PD patients among the entire dialysis patient population was $2.9 \%$, a decrease of $0.1 \%$ from the previous year. The number of patients who underwent a nonPD modality but despite having a PD catheter, most of whom are considered to have undergone only peritoneal lavage, was 278 and it was a decrease of 14 from the previous year. The number of new patients who were started PD in 2014 but switched to another method in the same year was 193, an increase of 19 from the previous year. The number of patients on the combination therapy of $\mathrm{PD}$ and HD or HDF was 1913, a decrease of 7 from the previous year (Table 1).

\section{Current status of the combination therapy of $P D+H D(F)$ with respect to $P D$ vintage}

To the questions regarding PD vintage and current status of PD + HD(F), 5678 patients responded. The percentage of patients who underwent $\mathrm{PD}+\mathrm{HD}(\mathrm{F})$ increased with
PD vintage ( $<1$ year, $3.3 \%$; $1-<2$ years, $10.1 \%$; $2-<4$ years, $16.3 \%$; $4-<6$ years, $26.9 \%$; $6-<8$ years, $40.9 \%$; $8-<10$ years, $53.5 \%$; and $\geq 10$ years, $58.7 \%$ ). Regarding the frequency of $\mathrm{HD}(\mathrm{F})$, the majority of the PD patients underwent $\mathrm{HD}(\mathrm{F})$ once a week (nearly $82.8 \%$ ) (Table 2 ).

\section{Changing maneuver of PD fluids}

To the questions regarding the method of PD solution exchange, 4417 of the PD-only patients responded. The number of PD patients who performed completely manual PD fluid exchanges was 1422 (32.2\%). The number of PD patients who used a double-bag system with ultraviolet light irradiation was 2322 (52.6\%), and the number of those who used the same system but with a sterile connecting device was 607 (13.7\%) (Table 3).

\section{Use or nonuse of $A P D$ machine with respect to $P D$ vintage}

Among the PD-only patients, 4446 responded to the questions regarding their PD vintage and use or nonuse of an APD machine. The percentage of PD-only patients who used an APD machine was $45.2 \%$. The percentages of PD-only patients who used an APD machine were $\geq 40 \%$ for PD vintages of $<6$ years $(<1$ year, $47.2 \%$; $1-$ $<2$ years, $50.0 \%$; $2-<4$ years, $44.2 \%$; and $4-<6$ years, 44.4\%). However, the percentage of PD-only patients who used an APD machine decreased to around 30\% for PD vintages of $\geq 6$ years ( $\geq 10$ years, $31.7 \%$ ) (Table 4 ).

\section{Number of hours of PD session per day with respect to PD vintage}

Among the PD-only patients, 4244 responded to the questions regarding their $\mathrm{PD}$ vintage and $\mathrm{PD}$ treatment time per day. The percentage of patients who underwent PD for the whole day $(24 \mathrm{~h})$ was $55.5 \%$. The percentages of patients who underwent PD for the whole day tended to increase with PD vintage ( $<1$ year, $42.8 \% ; 8-<10$ years, $79.6 \%$; and $\geq 10$ years, $76.0 \%$ ) (Table 5 ).

Table 13 Center's peritonitis rate

\begin{tabular}{lllllllllll}
\hline $\begin{array}{l}\text { Peritonitis rate } \\
\text { (episodes per year per facility) }\end{array}$ & $0 \sim$ & $1.0 \sim$ & $2.0 \sim$ & $3.0 \sim$ & $4.0 \sim$ & $5.0 \sim$ & Subtotal & $\begin{array}{l}\text { No information } \\
\text { available }\end{array}$ & $\begin{array}{c}\text { Total } \\
\text { Mean }\end{array}$ \\
\hline Number of facilities (\%) & $195(85.9)$ & $25(11.0)$ & $5(2.2)$ & $1(0.4)$ & $0(0.0)$ & $1(0.4)$ & $227(100.0)$ & 263 & 490 & 0.21 \\
\hline
\end{tabular}

These data were obtained from the PD-only patients in the patient survey

Center's peritonitis rate per patient-year $=$ (Peritonitis episodes in 2014 in all patients in the facility $\div$ Total months on PD in 2014 in all patients in the facility) $\times 12$ 
Table 14 Patient's ESI rate

\begin{tabular}{|c|c|c|c|c|c|c|c|c|c|c|}
\hline ESI episodes per patient-year & 0 & $1.0-<2.0$ & $2.0-<3.0$ & $3.0-<4.0$ & $4.0-<5.0$ & $\geq 5.0$ & Subtotal & $\begin{array}{l}\text { Unspecified/no } \\
\text { information available }\end{array}$ & Total & Mean \\
\hline umber of patients (\%) & $3465(80.8)$ & 495 (11.5) & $159(3.7)$ & $58(1.4)$ & $40(0.9)$ & $72(1.7)$ & $4289(100.0)$ & 2899 & 7188 & 0.40 \\
\hline
\end{tabular}

These data were obtained from the PD-only patients in the patient survey

The patient's ESI rate per patient-year $=($ ESI episodes in 2014 in all subjects $\div$ Total months on PD in 2014 in all subjects $) \times 12$

\section{Urine output and ultrafiltration volume by PD Urine output by PD vintage}

To the questions regarding urine output and PD vintage, 3702 of the PD-only patients responded. The mean urine output of the PD patients was $748.9 \mathrm{~mL} /$ day. The urine output tended to decrease with increasing $\mathrm{PD}$ vintage (<1 year, $970.0 \mathrm{~mL} /$ day and $\geq 10$ years, $239.5 \mathrm{~mL} /$ day) (Table 6).

\section{Ultrafiltration volume by $P D$ by $P D$ vintage}

To the questions regarding the ultrafiltration volume by PD and PD vintage, 3914 of the PD-only patients responded. The mean ultrafiltration volume by $\mathrm{PD}$ was $615.8 \mathrm{~mL} /$ day. The mean ultrafiltration volume by $\mathrm{PD}$ tended to increase with $\mathrm{PD}$ vintage $(<1$ year, $450.3 \mathrm{~mL} /$ day and $\geq 10$ years, $838.5 \mathrm{~mL} /$ day) (Table 7 ).

\section{Peritoneal equilibration test (PET) History of PET}

To the questions regarding the history of PET, 4390 of the PD-only patients responded. Among these patients, 1885 (42.9\%) underwent a standard PET and 992 (22.6\%) underwent a fast PET; that is, a total of 2877 (65.5\%) underwent PET (Table 8).

\section{PET D/P Cr ratio and type of PD fluid}

To the questions regarding the type of PD fluid, 4508 of the PD-only patients responded. Among these patients, $2782(61.7 \%)$ used 1.5 or $2.5 \%$ dextrose and only 10 $(0.2 \%)$ used $4.25 \%$ dextrose. The number of patients who used icodextrin was 1719 (38.1\%). The percentage of patients who used icodextrin increased with PET D/P Cr ratio $(<0.5,26.0 \%$; $0.5-<0.65,30.5 \%$; $0.65-<0.81,45.5 \%$; and $\geq 0.81,56.7 \%$ ) (Table 9 ).

\section{Residual renal $\mathrm{Kt} / \mathrm{V}$ and $\mathrm{PD} \mathrm{Kt} / \mathrm{V}$ \\ Residual renal $\mathrm{Kt} / \mathrm{V}$ by $\mathrm{PD}$ vintage}

To the questions regarding the residual renal Kt/V and $\mathrm{PD}$ vintage, 1764 of the $\mathrm{PD}$-only patients responded. The mean residual renal $\mathrm{Kt} / \mathrm{V}$ was 0.66 . The mean residual renal $\mathrm{Kt} / \mathrm{V}$ decreased with increasing $\mathrm{PD}$ vintage of $<8$. For patients with $P D$ vintage of $\geq 8$, the residual renal $\mathrm{Kt} / \mathrm{V}$ was considered to be varied significantly among patients (Table 10).

\section{$P D K t / V$ by $P D$ vintage}

To the questions regarding PD Kt/V and PD vintage, 1937 of the PD-only patients responded. The mean PD Kt/V was 1.31. The mean PD Kt/V tended to increase with increasing PD vintage ( $<1$ year, 1.10 and $\geq 10$ years, 1.51) (Table 11).

\section{Peritonitis and catheter exit-site infections}

Peritonitis is defined as a white blood cell count of $\geq 100 / \mu \mathrm{L}$ (neutrophil, $\geq 50 \%$ ) in waste PD fluid. A catheter exit-site infection is defined by the presence of purulent drainage from the exit site. The rates of peritonitis and catheter exit-site infections were calculated in the PD-only patients using the following formulae.

\section{Patient's peritonitis rate}

The patient's peritonitis rate per patient-year was calculated as follows,

The patient's peritonitis rate per patient-year

$=$ (Peritonitis episodes in 2014 in all subjects

$\div$ Total months on PD in 2014 in all subjects $) \times 12$

According to the International Society for Peritoneal Dialysis (ISPD) guidelines (Peritoneal Dialysis-Related Infection Recommendations: 2010 Update) [5], "the center's peritonitis rate should be no more than 1 episode every 18 months (0.67 per patient-year)."

To the questions regarding peritonitis, 4301 of the PD-only patients responded. The mean peritonitis rate was 0.21 per patient-year ( 1 episode every 57.1 patientmonths). This was much lower than the recommendation in the ISPD guidelines. The number of patients who did not develop peritonitis in 2014 was 3758 (87.4\%). The number of patients with a peritonitis rate

Table 15 Center's ESI rate

\begin{tabular}{|c|c|c|c|c|c|c|c|c|c|c|}
\hline Episodes of ESI per patient-year & $0 \sim$ & $1.0 \sim$ & $2.0 \sim$ & $3.0 \sim$ & $4.0 \sim$ & $5.0 \sim$ & Subtotal & $\begin{array}{l}\text { No information } \\
\text { available }\end{array}$ & Total & Mean \\
\hline Number of facilities (\%) & $191(75.9)$ & $51(15.2)$ & $11(5.2)$ & $1(1.1)$ & $3(0.7)$ & $4(1.9)$ & $261(100.0)$ & 229 & 490 & 0.40 \\
\hline
\end{tabular}

These data were obtained from the PD-only patients in the patient survey

The center's ESI rate per patient-year $=($ ESI episodes in 2014 in all patients in the center $\div$ Total months on PD in 2014 in all patients in the center) $\times 12$ 
of $1.0-<2.0$ was $400(9.3 \%)$ and that with a peritonitis rate of $\geq 2.0$ was 143 (3.3\%) (Table 12 ).

\section{Center's peritonitis rate}

The center's peritonitis rate was calculated as follows,

The center's peritonitis rate per patient-year

$=$ (Peritonitis episodes in 2014 in all patients in the center

$\div$ Total months on PD in 2014 in all patients in the center) $\times 12$

On the basis of the valid responses obtained from 227 centers, the mean center's peritonitis rate was 0.21 per patient-year (1 episode each 57.1 patientmonths) (Table 13).

\section{Patient's catheter exit-site infection (ESI) rates}

The patient's ESI rate was calculated as follows,

$$
\begin{aligned}
& \text { The patient's ESI rate per patient-year } \\
& =(\text { ESI episodes in } 2014 \text { in all subjects } \\
& \div \text { Total months on PD in } 2014 \text { in all subjects }) \times 12
\end{aligned}
$$

To the questions regarding ESI, 4289 of the PD-only patients responded. The mean patient's ESI rate in the PD-only dialysis patients was 0.40 per patient-year ( 1 episode every 30.0 patient-months). The number of patients who did not develop ESI in 2014 was 3465 (80.8\%). The number of patients with ESI rate of 1.0 $<2.0$ was $495(11.5 \%)$ and that with ESI rate of $\geq 2.0$ was 329 (7.7\%) (Table 14).

\section{Center's ESI rate}

The center's ESI rate was calculated as follows.

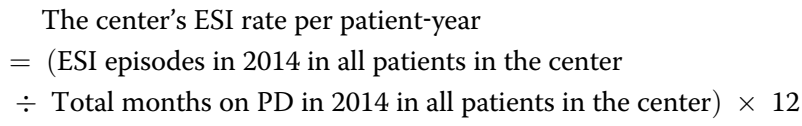

On the basis of the valid responses obtained from 261 centers, the mean center's ESI rate was 0.40 per patientyear (1 episode each 30.0 patient-months) (Table 15).

\section{Encapsulating peritoneal sclerosis (EPS) History of EPS in the patients with PD history}

The history of EPS and the treatments for EPS, surgical treatment and/or steroids, were surveyed on the patients on PD and the patients with past PD history currently on another dialysis modality. Among the 12,865 patients who responded to the questions regarding their history of EPS, 676 (5.3\%) had a history of EPS. Among these 676 patients, $541(80.0 \%)$ had received surgical treatments (Table 16).

\section{History of EPS by PD vintage}

Responses to the questions regarding PD vintage and EPS history were obtained from 4917 patients. The percentages of patients with a history of EPS who had undergone PD for $<6$ years were low $(<1$ year, $0.4 \% ; 1-<2$ years, $0.7 \%$; $2-<4$ years, $0.5 \%$; and $4-<6$ years, $0.3 \%)$. However, the percentages of such patients who had undergone PD for a longer duration increased to around $1 \%(6-<8$ years, $1.6 \%$;

\begin{tabular}{|c|c|c|c|c|c|c|c|c|c|}
\hline \multirow[t]{2}{*}{ Treatment for EPS } & \multirow[t]{2}{*}{ EPS (-) } & \multicolumn{4}{|l|}{ EPS (+) } & \multirow[t]{2}{*}{ Subtotal } & \multirow[t]{2}{*}{ Unspecified } & \multirow{2}{*}{$\begin{array}{l}\text { No } \\
\text { information } \\
\text { available }\end{array}$} & \multirow[t]{2}{*}{ Total } \\
\hline & & $\begin{array}{l}\text { Surgery }(+) \\
\text { steroids (+) }\end{array}$ & $\begin{array}{l}\text { Surgery (+) } \\
\text { steroids }(-)\end{array}$ & $\begin{array}{l}\text { Surgery (-) } \\
\text { steroids (+) }\end{array}$ & $\begin{array}{l}\text { Surgery }(-) \\
\text { steroids (-) }\end{array}$ & & & & \\
\hline In-center HD (\%) & $\begin{array}{l}5051 \\
(91.2)\end{array}$ & $376(6.8)$ & $12(0.2)$ & $56(1.0)$ & $46(0.8)$ & $\begin{array}{l}5541 \\
(100.0)\end{array}$ & 198 & 730 & 6469 \\
\hline HDF (\%) & $\begin{array}{l}1250 \\
(90.5)\end{array}$ & $104(7.5)$ & $3(0.2)$ & $9(0.7)$ & $15(1.1)$ & $\begin{array}{l}1381 \\
(100.0)\end{array}$ & 35 & 161 & 1577 \\
\hline Hemofiltration (\%) & $1(100.0)$ & - & - & - & - & $1(100.0)$ & - & - & 1 \\
\hline $\begin{array}{l}\text { Hemoadsorption } \\
\text { (\%) }\end{array}$ & $46(79.3)$ & $8(13.8)$ & $1(1.7)$ & - & $3(5.2)$ & $\begin{array}{l}58 \\
(100.0)\end{array}$ & 4 & 3 & 65 \\
\hline Home HD (\%) & $72(98.6)$ & $1(1.4)$ & - & - & - & $\begin{array}{l}73 \\
(100.0)\end{array}$ & - & 4 & 77 \\
\hline PD (\%) & $\begin{array}{l}5769 \\
(99.3)\end{array}$ & $36(0.6)$ & - & $3(0.1)$ & $3(0.1)$ & $\begin{array}{l}5811 \\
(100.0)\end{array}$ & 67 & 3063 & 8941 \\
\hline Subtotal (\%) & $\begin{array}{l}12,189 \\
(94.7)\end{array}$ & $525(4.1)$ & $16(0.1)$ & $68(0.5)$ & $67(0.5)$ & $\begin{array}{l}12,865 \\
(100.0)\end{array}$ & 304 & 3961 & 17,130 \\
\hline $\begin{array}{l}\text { No information } \\
\text { available (\%) }\end{array}$ & - & - & - & - & - & - & - & - & - \\
\hline Total (\%) & $\begin{array}{l}12,189 \\
(94.7)\end{array}$ & $525(4.2)$ & $16(0.2)$ & $68(0.6)$ & $67(0.4)$ & $\begin{array}{l}12,865 \\
(100.0)\end{array}$ & 304 & 3961 & 17,130 \\
\hline
\end{tabular}
$8-<10$ years, $1.1 \%$; and $\geq 10$ years, $0.9 \%$ ) (Table 17 ).

Table 16 PD patient distribution, by treatment for EPS and dialysis modality

These data were obtained from the patients on PD and the patients with past PD history currently on another dialysis modality 


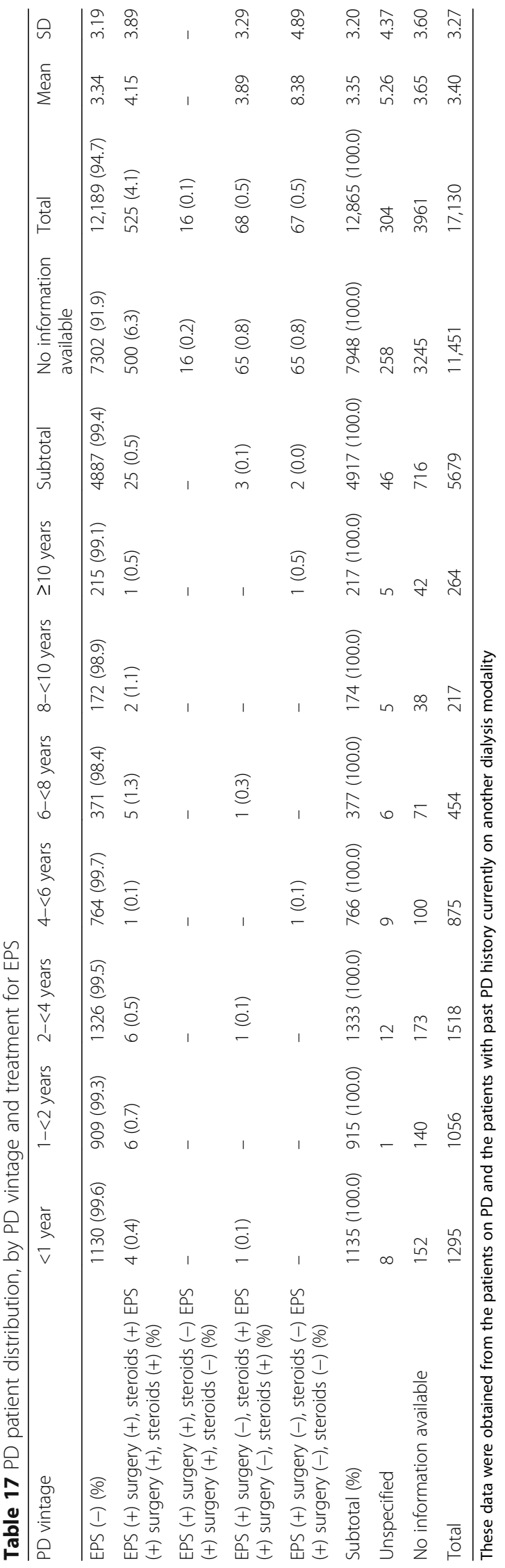




\section{Conclusions}

The number of PD patients has been stable around $9000 \sim 10,000$ in these 10 years, and the penetration rate of PD among all dialysis patients was just $2.9 \%$, which is one of the lowest numbers in the world. There were several unique points in the current status of PD therapy in Japan compared with other many countries. One of them was the combination therapy of PD and other dialysis modality and $21 \%$ of the PD patients were on the combination therapy. The second is lower PD dialysis dose as the mean PD Kt/V was 1.31, and it was supposed to be smaller than that from the world reports. The third is the lower risk of PD-related infections as the patient's peritonitis rate was 0.21 per patient-year and it was smaller than that of ISPD guideline. The final is about EPS. The percentage of the patients with the history of EPS among the patients with current and past PD treatment was $5.3 \%$, and $80 \%$ of them had received the surgical treatment. The PD registry in Japan has clarified unique points in the current status of PD therapy in Japan and the differences from the trends in the other countries in the world. Based on the further analysis of the PD registry data, we would like to improve the quality of PD therapy in Japan and send messages about the merits of our therapeutic policy to the world.

\section{Abbreviations \\ APD: Automated peritoneal dialysis; BUN: Blood urea nitrogen; CRDR: The committee of renal data registry; CRP: C-reactive protein; D/P Cr: Dialysate/ plasma creatinine; EPS: Encapsulating peritoneal sclerosis; ESI: Exit-site infection; HDF: Hemodiafiltration; ISPD: The International Society for Peritoneal Dialysis; JRDR: JSDT renal data registry; JSDT: Japanese Society for Dialysis Therapy; Kt/N: Index for standardized dialysis dose defined as; K: urea clearance; PD: Peritoneal dialysis; PET: Peritoneal equilibration test; PTH: Parathyroid hormone; t: Dialysis time, V: body fluid volume; USB: Universal serial bus}

\section{Acknowledgements \\ We owe the completion of this survey to the efforts of the members of the subcommittee of local cooperation mentioned as follows and the staff members of dialysis facilities who participated in the survey and responded to the questionnaires. We would like to express our deepest gratitude to all these people. \\ District Cooperative Committee in JRDR \\ Noritomo Itami, Tetsuya Kawata, Chikara Oyama, Koji Seino, Toshinobu Sato, Shigeru Sato, Minoru Ito, Masaaki Nakayama, Atsushi Ueda, Takashi Yagisawa, Tetsuo Ando, Tomonari Ogawa, Hiroo Kumagai, Makoto Ogura, Takahiro Mochizuki, Ryoichi Ando, Kazuyoshi Okada, Tetsuya Kashiwagi, Chieko Hamada, Yugo Shibagaki, Nobuhito Hirawa, Junichiro Kazama, Yoichi Ishida, Hitoshi Yokoyama, Ryoichi Miyazaki, Mizuya Fukasawa, Masaki Nagasawa, Teppei Matsuoka, Akihiko Kato, Noriko Mori, Yasuhiko Ito, Hirotake Kasuga, Sukenari Koyabu, Takashi Udu, Tetsuya Hashimoto, Masaaki Inaba, Terumasa Hayashi, Tomoyuki Yamakawa, Shinichi Nishi, Akira Fujimori, Tatsuo Yoneda, Shigeo Negi, Akihisa Nakaoka, Takafumi Ito, Hitoshi Sugiyama, Takao Masaki, Yutaka Nitta, Hirofumi Hashimoto, Masato Yamanaka, Masaharu Kan, Kazumichi Ota, Masahito Tamura, Koji Mitsuiki, Yuji Ikeda, Masaharu Nishikido, Akira Miyata, Tadashi Tomo, Shoichi Fujimoto, Tsuyoshi Nosaki, Yoshinori Oshiro}

\section{Funding}

There are no funding for the current study.

All efforts and costs for the 2014 JRDR survey and making the report were totally given by JSDT.

\section{Availability of data and materials}

When anyone wants to use the data and materials from the current manuscript without modifications, all data and materials are freely available with stating "data from JSDT."

When anyone wants to use the data and materials from the current manuscript with modifications, any re-calculations or something, they have to state the following sentence in their publication. "The data reported here have been provided by Japanese Society for Dialysis Therapy (JSDT). The interpretation and reporting of these data are the responsibility of the authors and in no way should be seen as an official policy or interpretation of the JSDT."

\section{Authors' contributions}

IM was the director of CRDR in 2014 and directed all of the 2014 JRDR survey. IM and TH finalized the results of the survey and made this manuscript. SO and AW designed the survey sheets and made a special program mounted in MS Excel worksheet for the convenience of selfassessment for the dialysis quality of each dialysis facility. SN, NK, and TH had the responsibilities on the data analysis. KW had the responsibility on the ethical aspect of the JRDR survey. KN was the president of the JSDT in 2014 and checked all the results from the 2014 JRDR survey and approved them to be published. All authors read and approved the final manuscript.

\section{Competing interests}

The authors declare that they have no competing interests.

\section{Consent for publication}

Follow the "Availability of data and materials."

Ethics approval and consent to participate

The JSDT registry was approved by the ethical committee of JSDT; the approval no. is 1 .

The aims of JSDT Renal Data Registry (JRDR) were well explained for the participated dialysis patients through the dialysis facilities.

It does not always need to get the documented approval form from the patients because all collected data were existing one and there were no new interventions.

The original data had been totally anonymized so there are no risks for deteriorating the privacy of the dialysis facilities and the patients.

The data presented in the current manuscript does not contain any images, videos, and voice recording which might have a risk for identifying an individual.

\section{Author details}

${ }^{1}$ Committee of Renal Data Registry (CRDR), Japanese Society for Dialysis Therapy (JSDT), Aramido Building 2F, 2-38-21 Hongo, Bunkyo-ku, Tokyo 113-0033, Japan. ² ubcommittee of Statical Analysis of CRDR, Japanese Society for Dialysis Therapy, Tokyo, Japan. ${ }^{3}$ Japanese Society for Dialysis Therapy, Tokyo, Japan. ${ }^{4}$ Department Nephrology, Yabuki Hospital, 4-4-5 Shima Kita, Yamagata City, Yamagata 990-0885, Japan.

Received: 25 January 2017 Accepted: 24 February 2017

Published online: 15 May 2017

\section{References}

1. Nakai S. History of statistical survey of the Japanese Society for Dialysis Therapy. J Jpn Soc Dial Ther. 2010;43:119-52 (in Japanese).

2. Nakai S, Iseki K, Itami N, Ogata S, Kazama JJ, Kimata N, et al. Overview of regular dialysis treatment in Japan (as of 31 December 2009). Ther Apher Dial. 2012;16:11-53.

3. Masakane I, Nakai S, Ogata S, Kimata N, Hanafusa N, Hamano T, et al. An overview of regular dialysis treatment in Japan (as of 31 December 2013). Ther Apher Dial. 2015;19:540-74.

4. Masakane I, Nakai S, Ogata S, Kimata N, Hanafusa N, Hamano T, et al. Overview of regular dialysis treatment in Japan (as of 31 December 2014). J Jpn Soc Dial Ther. 2016;49:1-34

5. Li PK, Szeto CC, Piraino B, Bernardini J, Figueiredo AE, Gupta A, et al. Peritoneal dialysis-related infections recommendations: 2010 update. Perit Dial Int. 2010;30:393-423. 